\title{
Convergence of two major pathophysiologic mechanisms in nasal polyposis: immune response to Staphylococcus aureus and airway remodeling
}

\author{
Rogério Pezato ${ }^{1,2^{*}}$, Leonardo Balsalobre ${ }^{1}$, Milena Lima ${ }^{3}$, Thiago F P Bezerra ${ }^{4}$, Richard L Voegels ${ }^{4}$, \\ Luis Carlos Gregório ${ }^{1}$, Aldo Cassol Stamm ${ }^{1}$ and Thibaut van Zele ${ }^{2}$
}

\begin{abstract}
This review is addressed two pathophysiologic mechanisms implicated in the pathogenesis of nasal polyposis: the unique remodeling process found in nasal polyp tissue and the immune response of patients with nasal polyposis to Staphylococcus aureus.

These two theories converge to the same direction in different aspects, including decreased extracellular matrix production, impaired T regulation and favoring of a Th2 immune response.

In patients with nasal polyposis, an exaggerated immune response to Staphylococcus aureus may aggravate the airway remodeling process.
\end{abstract}

Keywords: Airway remodeling, Superantigens, Nasal polyps

In this article, we will discuss two important mechanisms implicated in the pathophysiology of nasal polyposis that have recently received much research attention, and highlight aspects in which these mechanisms intersect.

This review clearly shows the potential for exacerbation of the nasal polyp remodelling process due to an immune response to Staphylococcus aureus.

\section{Characteristics of the airway remodelling process in chronic rhinosinusitis with nasal polyps (CRSwNP)}

Many authors consider the lower and upper airways as a continuum [1] of tissue that shares the same pseudostratified ciliated columnar epithelium lining. Furthermore, the "one airway, one disease" concept is widely known and established the world over. Asthma and nasal polyposis essentially share the same inflammatory characteristics: a predominance of eosinophil infiltration, goblet cell hyperplasia, and a Th2-cell immune response $[2,3]$. The simi-

\footnotetext{
* Correspondence: pezatobau@ig.com.br

'Department of Otolaryngology - Head and Neck Surgery of Federal University of São Paulo, Rua Maestro Antão Fernandes, 173, Jd São Bento, São Paulo, SP02526-060, Brazil

2Department of Oto-Rhino-Laryngology, Ghent University Hospital, Ghent University, Ghent, Belgium

Full list of author information is available at the end of the article
}

larities between the upper and lower airway mucosa and the inflammatory processes that affect them, associated with the fact that polyposis in the lung mucosa is virtually unheard of, make the bronchial mucosa an extraordinary model for the study of nasal polyposis [4].

There are some important differences in the remodeling process between the lower and upper airway: nasal epithelial disruption, basement membrane pseudothickening, and elastase-positive cells, which are less numerous in the nasal mucosa than in lung mucosa [5]. Nasal polyposis also features major edema, albumin-filled pseudocysts, and alpha-2-macroglobulin; in CRSwNP, soft tissue edema and overgrowth of nasal mucosa predominate [6]. Conversely, in chronic rhinosinusitis without nasal polyps (CRSsNP), there is mucosal fibrosis with an increase in collagen.

The importance of the epithelium is demonstrated experimentally when injured epithelium results in impaired repair and an increase in the production and release of TGF- $\beta$ [7].

TGF- $\beta 1$ is a cytokine produced by most immune cells, fibroblasts and many other cells; it is considered a pleiotropic and multifunctional growth factor with important immunomodulatory and fibrogenic effects. 
The function of TGF- $\$ 1$, however, does not seem to be one-dimensional. A dual anti-inflammatory and profibrotic role may occur [8].

The role of TGF-ß1 expression in nasal polyposis is still controversial. Some authors advocate that TGF-ß1 is increased in nasal polyposis compared to healthy nasal mucosa or CRSsNP, but these studies used immunohistochemistry to support their findings $[9,10]$, while others have reported opposite findings with use of quantitative methods such as Elisa or PCR in nasal tissue homogenates $[2,11]$.

It is also important to consider the fact that, in nasal polyposis, TGF- $ß 1$ expression patterns are different in the stroma and epithelium, being higher and lower respectively as compared with control nasal mucosa.

TGF- 31 plays an important role in the balance of fibrinolysis and fibrogenesis and, consequently, on the extracellular matrix (ECM).

In NP tissue, matrix metalloproteinase 7 (MMP-7) and matrix metalloproteinase 9 (MMP-9) levels are increased and tissue inhibitor of metalloproteinases 1 (TIMP-1) levels are decreased as compared with normal nasal mucosa [12].

This imbalance can be partially explained by the lack of TGF-ß1 in NP and its inhibitory effect on MMP-9 activity via TIMP-1 release [13].

For the same reason, in NP, TGF- $\beta_{1}$-activated PAI-1 (plasminogen activator inhibitor-1) is decreased and, consequently, plasminogen activator and MMP levels are increased as compared with controls and patients with CRSsNP [14].

The hypothesis that CRSsNP is characterized by fibrosis, high levels of TGF- $\beta$ and increased Treg activity, whereas NP is characterized by edema, a lack of extracellular matrix, and low TGF- $\beta$ levels and Treg activity $[4,6]$ is the cornerstone of the chronic rhinosinusitis remodelling process, according to recent studies.

\section{Impact of Staphylococcus aureus superantigens on chronic rhinosinusitis with nasal polyps}

NP is a severe chronic inflammatory disease involving the paranasal sinuses that is frequently associated with asthma and aspirin sensitivity. NP in combination with aspirininduced asthma (AIA) represents the most severe form of airway inflammation within the group of patients with NP. The pathophysiology of NP is not fully understood, and is most likely to be multifactorial. Over the years, this disease has frequently been linked to staphylococcal colonization and, particularly, to bacterial products such as enterotoxins from Staphylococcus aureus.

Staphylococcal species are the most prevalent bacteria that have been isolated from the nasal mucus of white patients with NP. An increased colonization rate of $S$. aureus has been demonstrated in patients with NP (63.6\%), but could not be demonstrated in patients with chronic rhinosinusitis without polyps (27.3\%) as compared with control subjects. In patients with NP and comorbid asthma or aspirin sensitivity, colonization rates were further increased, up to $80 \%$ [15]. S. aureus has also been detected in the submucosal space by peptide nucleic acidfluorescence in situ hybridization (PNA-FISH) in patients with NP, and especially in subgroups of NP with aspirin sensitivity $[16,17]$.

These are both potential reservoirs for superantigen release in the sinuses. Th2-polarized inflammation with a resultant eosinophilic inflammatory milieu has also been linked to the presence of $S$. aureus biofilms. This may occur both dependently and independently of the superantigen pathway, implying a direct link between microorganism and host [18]. A different form of colonization by Staphylococcus aureus, through biofilms, has received attention recently.

A biofilm is a group of adherent bacteria irreversibly anchored to a surface and enclosed in a matrix of exopolysaccharide $[19,20]$.

Fungal elements associated with bacteria within biofilms of CRS patients have been demonstrated, an association that could lead to enhanced virulence of bacterial biofilms [21].

Biofilm-grown bacteria can be very resistant to fluctuations in moisture, $\mathrm{pH}$ and temperature. They are also highly resistant to antibiotic therapy, which may explain chronic infections refractory to clinical management $[19,20]$.

Foreman et al. confirmed the hypothesis that biofilms would be present in NP patients as a nidus from which planktonic S. aureus and superantigens are released into the paranasal sinuses [18].

Staphylococcus aureus biofilms in NP patients have been shown to result in eosinophilic inflammation and significantly higher levels of IL-5 and ECP. Staphylococcal superantigen-specific IgE was associated with a Th2skewed response and a significantly elevated total IgE, IL-5 and ECP. The presence of Staphylococcus aureus biofilms was also associated both with worse symptoms and worse Lund-Mackay scores in patients with NP.

Biofilms have also been detected in control groups composed of patients who underwent septoplasty surgery due to nasal obstruction [22].

The mechanisms of this increased bacterial colonization in NP are unclear, but recent data suggest that a defect in the phagocytic system in NP might contribute to increased S. aureus colonization [23].

The pathogenic impact of $S$. aureus in NP has been mainly attributed to virulence factors secreted by S. aureus, such as staphylococcal enterotoxins. However, screening for staphylococcal superantigens genes showed no correlation with the presence or severity of NP. This suggests that the specific immune response of the host to $S$. aureus 
colonization, rather than the panel of enterotoxin genes present, determines the pathophysiology of NP [24,25].

Staphylococcus aureus enterotoxins (SEs) elicit a massive inflammatory reaction resulting in a polyclonal activation of $\mathrm{T}$ and B-lymphocytes independent of the specific adaptive immune response. Clonal expansion of the corresponding V- $\beta$ signature region of TCRs might play a major role in the pathogenesis of NP. A significant, specific TCR-V $\beta$ expansion linked to the presence of serum IgE to staphylococcal toxins was observed in NP tissue, suggesting a superantigen reaction [26].

SEB stimulation in cultured nasal polyps increases levels of IFN- $\gamma$ and IL-4, but not of IL-10. It also upregulates mRNA expression of T-bet and GATA-3, but not that of Foxp3 or RORyt, which indicates that SEB is able to affect $\mathrm{T}_{\text {reg }}$ activity and cause $\mathrm{T}_{\text {reg }}$ insufficiency. SEB stimulation also increases levels of various pro-inflammatory factors, including IL-2, IL-6, and IL-8, in cultured nasal polyps; these, in turn, also affect $\mathrm{T}_{\text {reg }}$ activity $[27,28]$.

A second mechanism by which the local inflammatory response can be upregulated is specific IgE directed against $S$. aureus enterotoxins. IgE antibodies to $S$. aureus enterotoxins were present in $28 \%$ of polyp samples, with rates as high as $80 \%$ in the subgroup of patients with asthma and aspirin sensitivity, as compared with $15 \%$ in control individuals and 6\% in patients with CRSsNP, respectively [15]. The presence of specific IgE against $S$. aureus enterotoxins was also coincident with higher levels of interleukin IL-5, eotaxin and ECP. Consistent with the increase in IL-5 and other Th2 cytokines, a significant increase in local IgE, IgA and IgG antibodies can be observed in polyp patients. Nasal polyp homogenates in which $S$. aureus enterotoxin-IgE antibodies were detectable had significantly greater concentrations of IgG, IgG4 and IgE than did those without $S$. aureus enterotoxinspecific IgE, positively correlating with IgE and the number of plasma cells, whereas the IgG2 fraction was significantly lower. These changes were not reflected in the serum of patients, confirming the notion of a local impact of superantigens - via direct action on B cells or indirectly via T-cell derived cytokines - on immunoglobulin synthesis. $S$ aureus superantigens can also induce the formation of polyclonal IgE directed against multiple inhalant allergens. These polyclonal IgE antibodies in NP are functional and able to activate mast cells ex vivo upon allergen challenge; apart from typical inhalant allergens, SEB may also serve as an allergen per se or as an indicator for superantigen impact on mucosal inflammation by maintaining a continuous activation of mast cells [29,30].

Patients with NP typically exhibit an upregulation of proinflammatory cysteinyl leukotrienes and a downregulation of prostaglandin E2, which is considered an antiinflammatory metabolite. NP patients who exhibit an immune response to $S$. aureus have an upregulated production of cysteinyl leukotrienes, leukotriene B4 and lipoxin A4 as compared with tissue from nasal polyp patients who were negative for $S$. aureus enterotoxinspecific IgE [31].

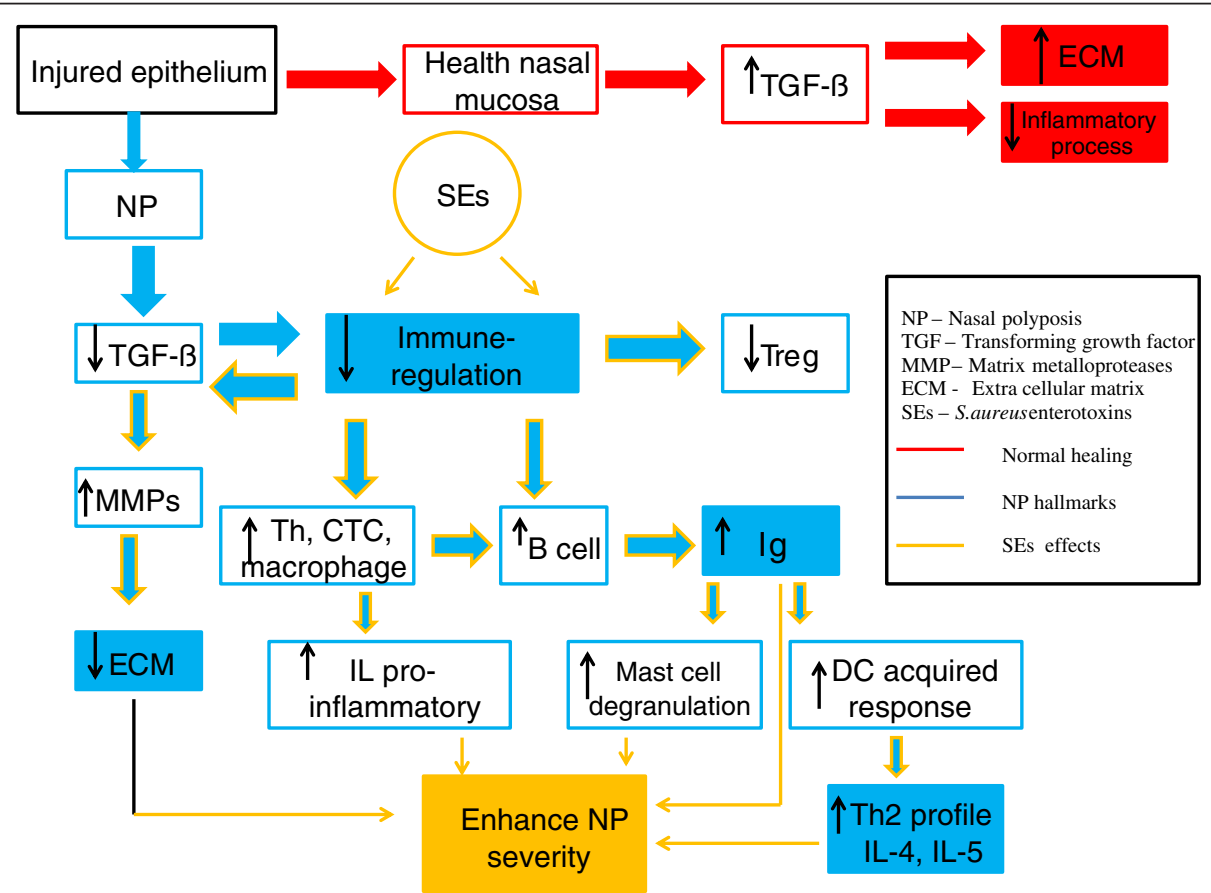

Figure 1 Illustration of the influence of Staphylococcus aureus (in orange) on the remodeling process in nasal polyposis. 
Nevertheless, a direct mechanism by which enterotoxins can modify prostanoid metabolism and related functions has yet to be identified.

The presence of specific IgE to staphylococcal enterotoxins is not only associated with a more severe and persistent inflammatory response, but is also linked to clearly identified clinical phenotypes of NP. Rates of both staphylococcal colonization and specific IgE to Staphylococcus are increased in NP patients if co-morbid asthma and aspirin intolerance are present [15].

Recently, the presence of IL- 5 and IgE antibodies to S. aureus enterotoxin (SE-IgE positivity) in human NP patients was shown to be associated with an increased risk of comorbid asthma, suggesting a decisive role of staphylococcal superantigens in amplifying and aggravating airway disease [32].

\section{The intersection of two paths}

The dual role of TGF- $\beta_{1}$ - increasing the extracellular matrix and acting as an anti-inflammatory cytokine - may be directly involved in the development of nasal polyposis. The lack of TGF- $\beta_{1}$ in nasal polyps could partially explain the soft tissue features (edema and pseudocyst formation) in the matrix and the severe inflammatory process found.

TGF- $\beta_{1}$ (and, probably, other members of the transforming growth factor family as well) inhibits activation and proliferation of helper $\mathrm{T}$ cells, cytotoxic $\mathrm{T}$ cells, macrophages, and monocytes, and reduces the secretion of pro-inflammatory cytokines [33,34]. It also interferes with antibody production by B cells [35].

TGF- $\beta$ is implicated in T-cell differentiation. $\mathrm{T}_{\text {reg }}$ differentiation is favored by TGF- $\beta$, but interleukins associated with pro-inflammatory cytokines (such as IL-21) favor Th17 differentiation [36].

The remodelling aspect in NP is a general phenomenon which is present in all subtypes of polyps (from European subjects, Chinese subjects, SE-mediated and non-SE-mediated polyps), but can be intensified by immune response to Staphylococcus aureus superantigens.

The fibrinolytic environment found in NP is worsened by MMP-2. MMP-9 levels have been found to increase after Staphylococcus aureus stimulation [37].

As described above, SEs increase Th activity directly via T-bet and GATA-3 expression, but not $\mathrm{T}_{\text {reg }}$ activity (via Foxp3), and indirectly foster a pro-inflammatory environment, which, together with TGF- $\beta$, can convert $\mathrm{T}_{\text {regs }}$ into Th cells. In nasal polyps, where there is a severely inflammatory local environment, there is an imbalance of the Th17/ $\mathrm{T}_{\text {reg }}$ ratio in the blood, with an increase in Th17 and decrease in $\mathrm{T}_{\text {regs }}$ [38].

SEs can per se lead to an increase in polyclonal IgE production that cannot be balanced by a TGF- $\beta_{1}$-dependent B-cell inhibitory effect, as it is decreased in NP. This "flood" of polyclonal IgE fosters the acquired immune response via dendritic cell FceRI and Fcy receptors and, consequently, a Th2 response [39].

The combination of IgE overexpression and lack of TGF- $ß$ can enhance mast cell degranulation [40], increase cysteinyl leukotriene production and eosinophil attraction and, consequently, exacerbate the Th2-mediated inflammatory process.

The overlap of these two pathophysiologic mechanisms clearly demonstrates that the course of nasal polyposis can be exacerbated through the combined action of innate (impaired remodeling of the nasal mucosa, immune responsiveness) and acquired (environmental exposures, such as Staphylococcus aureus) factors (Figure 1).

\section{Competing interests}

The authors declare that they have no competing interests.

\section{Authors' contribution}

RP, TFPB, TvanZ, ML, LB made substantial contributions to study conception and design. RP, TFPB, TvanZ, ML, LB were involved in drafting the manuscript. ACS, RLV, LCG were involved in revising the manuscript critically for important intellectual content. All authors have given final approval for the version to be published.

\section{Author details}

${ }^{1}$ Department of Otolaryngology - Head and Neck Surgery of Federal University of São Paulo, Rua Maestro Antão Fernandes, 173, Jd São Bento, São Paulo, SP02526-060, Brazil. Department of Oto-Rhino-Laryngology, Ghent University Hospital, Ghent University, Ghent, Belgium. ${ }^{3}$ Military Police Hospital, São Paulo, Brazil. ${ }^{4}$ Department of Otorhinolaryngology and Ophthalmology, University of São Paulo, São Paulo, Brazil.

Received: 21 November 2012 Accepted: 18 March 2013

Published: 28 March 2013

\section{References}

1. Cruz AA, Popov T, Pawankar R, Annesi-Maesano I, Fokkens W, Kemp J, Ohta K, Price D, Bousquet J: ARIA Initiative Scientific Committee. Common characteristics of upper and lower airways in rhinitis and asthma: ARIA update, in collaboration with GA(2)LEN. Allergy 2007, 62(Suppl 84):14-41.

2. Bachert C, Gevaert P, Holtappels G, Cuvelier C, van Cauwenberge P: Nasal polyposis: from cytokines to growth. Am J Rhinol 2000, 14(5):279-290.

3. McGee HS, Agrawal DK: Naturally occurring and inducible T-regulatory cells modulating immune response in allergic asthma. Am J Respir Crit Care Med 2009, 180(3):211-225.

4. Pezato R, Voegels RL: Why do we not find polyps in the lungs? Bronchial mucosa as a model in the treatment of polyposis. Med Hypotheses 2012, 78(4):468-470.

5. Bousquet J, Jacot W, Vignola AM, Bachert C, Van Cauwenberge P: Allergic rhinitis: a disease remodeling the upper airways? J Allergy Clin Immunol 2004, 113(1):43-49.

6. Li X, Meng J, Qiao X, Liu Y, Liu F, Zhang N, Zhang J, Holtappels G, Luo B, Zhou P, Zheng Y, Lin P, Liu S, Bachert C: Expression of TGF, matrix metalloproteinases, and tissue inhibitors in Chinese chronic rhinosinusitis. J Allergy Clin Immunol 2010, 125(5):1061-1068.

7. Holgate ST, Holloway J, Wilson S, Bucchieri F, Puddicombe S, Davies DE: Epithelial-mesenchymal communication in the pathogenesis of chronic asthma. Proc Am Thorac Soc 2004, 1(2):93-98.

8. Salib R, Howarth P: Transforming growth factor-B in allergic inflammatory disease of the upper airways: friend or foe? Clin Exp Allergy 2009, 39(8):1128-1135.

9. Hirschberg A, Jokuti A, Darvas Z, Almay K, Repassy G, Falus A: Pathogenesis of nasal polyposis by immunoglobulin $E$ and interleukin- 5 is complete by transforming growth factor-B1. Laryngoscope 2003, 113:120-124.

10. Wang Q-P, Escudier E, Roudot-Thoraval F, Al Samad I, Peynegre R, Coste A: Myofibroblast accumulation induced by transforming growth factor- $B$ is involved in the pathogenesis of nasal polyps. Laryngoscope 1997, 107:926-931. 
11. Figueiredo $C R$, Santos RP, Silva ID, Weckx LL: Microarray cDNA to identify inflammatory genes in nasal polyposis. Am J Rhinol 2007, 21(2):231-235.

12. Watelet JB, Bachert C, Claeys C, Van Cauwenberge P: Matrix metalloproteinases MMP-7, MMP-9 and their tissue inhibitor TIMP-1: expression in chronic sinusitis vs nasal polyposis. Allergy 2004, 59:54-60.

13. Lee YM, Kim SS, Kim HA, Suh YJ, Lee SK, Nahm DH, Park HS: Eosinophil inflammation of nasal polyp tissue: relationships with matrix metalloproteinases, tissue inhibitor of metalloproteinase-1, and transforming growth factor-beta1. J Korean Med Sci 2003, 18:97-102.

14. Sejima T, Holtappels $G$, Bachert $C$ : The expression of fibrinolytic components in chronic paranasal sinus disease. Am J Rhinol Allergy 2011, 25(1):1-6.

15. Van Zele T, Gevaert P, Watelet JB, Claeys G, Holtappels G, Claeys C, van Cauwenberge $P$, Bachert $C$ : Staphylococcus aureus colonization and lgE antibody formation to enterotoxins is increased in nasal polyposis. J Allergy Clin Immunol 2004, 114(4):981-983.

16. Corriveau MN, Zhang N, Holtappels G, Van Roy N, Bachert C: Detection of Staphylococcus aureus in nasal tissue with peptide nucleic acidfluorescence in situ hybridization. Am J Rhinol Allergy 2009, 23(5):461-465

17. Sachse F, Becker K, von Eiff C, Metze D, Rudack C: Staphylococcus aureus invades the epithelium in nasal polyposis and induces IL-6 in nasal epithelial cells in vitro. Allergy 2010, 65(11):1430-1437.

18. Foreman A, Holtappels G, Psaltis AJ, Jervis-Bardy J, Field J, Wormald PJ Bachert C: Adaptive immune responses in Staphylococcus aureus biofilm-associated chronic rhinosinusitis. Allergy 2011, 66(11):1449-1456.

19. Donlan RM: Biofilms: microbial life on surfaces. Emerg Infect Dis 2002 8(9):881-890.

20. Costerton JW, Stewart PS, Greenberg EP: Bacterial biofilms: a common cause of persistent infections. Science 1999, 284(5418):1318-1322.

21. Peters BM, Jabra-Rizk MA, Scheper MA, Leid JG, Costerton JW, Shirtliff ME: Microbial interactions and differential protein expression in Staphylococcus aureus -Candida albicans dual-species biofilms. FEMS Immunol Med Microbiol 2010, 59(3):493-503

22. Bezerra TFP, Padua FGM, Gebrim EMMS, Saldiva PH, Voegels RL: Biofilms in Chronic Rhinosinusitis with Nasal Polyps. Otolaryngol Head Neck Surg 2011, 144(4):612-616.

23. Krysko O, Holtappels G, Zhang N, Kubica M, Deswarte K, Derycke L, Claeys S, Hammad H, Brusselle GG, Vandenabeele P, Krysko DV, Bachert C: Alternatively activated macrophages and impaired phagocytosis of $\mathrm{S}$. aureus in chronic rhinosinusitis. Allergy 2011, 66(3):396-403.

24. Van Zele T, Vaneechoutte M, Holtappels G, Gevaert P, van Cauwenberge P, Bachert C: Detection of enterotoxin DNA in Staphylococcus aureus strains obtained from the middle meatus in controls and nasal polyp patients. Am J Rhinol 2008, 22(3):223-227.

25. Heymans F, Fischer A, Stow NW, Girard M, Vourexakis Z, Des Courtis A, Renzi G, Huggler E, Vlaminck S, Bonfils P, Mladina R, Lund V, Schrenzel J, François $P$, Lacroix JS: Screening for staphylococcal superantigen genes shows no correlation with the presence or the severity of chronic rhinosinusitis and nasal polyposis. PLoS One 2010, 5(3):e9525.

26. Tripathi A, Kern R, Conley DB, Seiberling K, Klemens JC, Harris KE, Suh L, Huang J, Grammer LC: Staphylococcal exotoxins and nasal polyposis: analysis of systemic and local responses. Am J Rhinol 2005, 19(4):327-333.

27. Xu G, Xia JH, Zhou H, Yu CZ, Zhang Y, Zuo KJ, Shi JB, Li HB: Interleukin-6 is essential for Staphylococcal exotoxin B-induced T regulatory cell insufficiency in nasal polyps. Clin Exp Allergy 2009, 39(6):829-837.

28. Patou J, Gevaert P, Van Zele T, Holtappels G, van Cauwenberge P, Bachert C: Staphylococcus aureus enterotoxin B, protein A, and lipoteichoic acid stimulations in nasal polyps. J Allergy Clin Immunol 2008, 121(1):110-115.

29. Zhang N, Holtappels G, Gevaert P, Patou J, Dhaliwal B, Gould H, Bachert C: Mucosal tissue polyclonal lgE is functional in response to allergen and SEB. Allergy 2011, 66(1):141-148.

30. Gevaert P, Holtappels G, Johansson SG, Cuvelier C, Cauwenberge P, Bachert C: Organization of secondary lymphoid tissue and local lgE formation to Staphylococcus aureus enterotoxins in nasal polyp tissue. Allergy 2005, 60(1):71-79.

31. Pérez-Novo CA, Claeys C, Van Zele T, Holtapples G, Van Cauwenberge P, Bachert C: Eicosanoid metabolism and eosinophilic inflammation in nasal polyp patients with immune response to Staphylococcus aureus enterotoxins. Am J Rhinol 2006, 20(4):456-460

32. Bachert C, Zhang N, Holtappels G, De Lobel L, van Cauwenberge P, Liu S, Lin P, Bousquet J, Van Steen: Presence of IL-5 protein and IgE antibodies to staphylococcal enterotoxins in nasal polyps is associated with comorbid asthma. J Allergy Clin Immunol 2010, 126(5):962-968.

33. Wahl SM, Hunt DA, Wong HL, Dougherty S, McCartney-Francis N, Wahl LM, Ellingsworth L, Schmidt JA, Hall G, Roberts AB, et al: Transforming growth factorbeta is a potent immunosuppressive agent that inhibits IL-1-dependent lymphocyte proliferation. J Immunol 1988, 140(9):3026-3032

34. Wahl SM, Wen J, Moutsopoulos N: TGF-beta: a mobile purveyor of immune privilege. Immunol Rev 2006, 213:213-227.

35. Lebman DA, Edmiston JS: The role of TGF-beta in growth, differentiation, and maturation of B lymphocytes. Microbes Infect 1999, 1(15):1297-1304.

36. Veldhoen M, Uyttenhove C, van Snick J, Helmby H, Westendorf A, Buer J, Martin B, Wilhelm C, Stockinger B: Transforming growth factor-beta 'reprograms' the differentiation of T helper 2 cells and promotes an interleukin 9-producing subset. Nat Immunol 2008, 9(12):1341-1346.

37. Wang JH, Kwon $\mathrm{HJ}$, Jang $\mathrm{YJ}$ : Staphylococcus aureus increases cytokine and matrix metalloproteinase expression in nasal mucosae of patients with chronic rhinosinusitis and nasal polyps. Am J Rhinol Allergy 2010, 24(6):422-427

38. Shen Y, Hong SL, Hu GH, Tang XY, Kou W, Pan CK: [Imbalance of Th17/Treg cell ratio in peripheral blood of patients with nasal polyposis and its clinical significance]. Xi Bao Yu Fen Zi Mian Yi Xue Za Zhi 2011, 27(12):1339-1342.

39. Blink SE, Fu YX: IgE regulates T helper cell differentiation through FcgammaRIII mediated dendritic cell cytokine modulation. Cell Immunol 2010, 264:54-60.

40. Ganeshan K, Bryce PJ: Regulatory T cells enhance mast cell production of IL-6 via surface-bound TGF- $\beta$. J Immunol 2012, 188(2):594-603.

doi:10.1186/1916-0216-42-27

Cite this article as: Pezato et al:: Convergence of two major pathophysiologic mechanisms in nasal polyposis: immune response to Staphylococcus aureus and airway remodeling. Journal of Otolaryngology Head and Neck Surgery 2013 42:27.

\section{Submit your next manuscript to BioMed Central and take full advantage of:}

- Convenient online submission

- Thorough peer review

- No space constraints or color figure charges

- Immediate publication on acceptance

- Inclusion in PubMed, CAS, Scopus and Google Scholar

- Research which is freely available for redistribution

Submit your manuscript at www.biomedcentral.com/submit
C) Biomed Central 